\title{
Constructing the Puerto Rico Self-Concept Scale: Problems and Procedures
}

\author{
Helen Abadzi and Sonia Florez \\ University of Texas at Arlington
}

The Puerto Rico self-concept scale was developed for the purpose of assessing the relationship of selfconcept with academic achievement and other school-related variables in Puerto Rico. An 88-item scale that can measure self-concept in the $4 \mathrm{th}, 7 \mathrm{th}$, and 10th grades was constructed. Empirical criterion keying was used for the development of items that were also adapted to the phraseology used by local students. After small-group testing, the 264item bank was administered to 2,445 students. Item analyses focused on item discrimination. Scores showed a low but significant correlation with previous' year's grade point average. Overall scale reliability was .93. A 34-item short form had overall reliability of .84 . Preliminary norms were prepared from existing data.

The educational community in the United States is becoming increasingly interested in the identification of personal variables that affect student performance. The self-concept of a student is considered an important variable related to academic achievement. Significant, though mostly moderate correlations have been demonstrated by several researchers between measurements of self-concept and student grades (Bloom, 1976; Brookhover, Patterson, \& Thomas, 1962; Campbell, 1967; Fink, 1962; Gill, 1969; Gordon, 1966; Purkey, 1970).

\footnotetext{
APPLIED PSYCHOLOGICAL MEASUREMENT Vol. 5, No. 2, Spring 1981, pp. 237-243

(C) Copyright 1981 Applied Psychological Measurement Inc. 0146-6216/81/020237-07\$1.35
}

Coppersmith (1967) considers the self-concept to be an individual's self-evaluation. More than 200 scales have been constructed that attempt to elicit this self-evaluation through various methods. Factor analyses carried out on some of the instruments indicate the presence of such factors as physical appearance, peer relations, school performance, leadership, and opinions about oneself (Muller \& Leonetti, 1972; Richmond \& White, 1971; Stanwyck \& Felker, 1971.

There seems to be a continuous interaction between the self and academic achievement, each directly influencing the other (Purkey, 1970). In evidence of this intricate relationship, the Commonwealth of Puerto Rico, Department of Education, developed a project whose purpose was to measure the self-concept of Puerto Rican students and to study its interactions with academic achievement. Accordingly, specifications for a self-concept scale were set.

The scale to be constructed should (1) make possible the assessment of the relationship between student self-concept and academic performance; (2) identify students with low self-concept at the 4th, $7 \mathrm{th}$, and 10 th grade level; and (4) measure changes from one grade level to the other. These specifications made it necessary to consider the development of a single form that could be used with 4 th, 7 th, and 10 th grade boys and girls and that would discriminate between students having high and low self-concepts. The 
construction of the scale consequently reflected what Cronbach (1970) calls the "bandwidth-fidelity dilemma": a test to be used with many grades and purposes might be less effective in measuring specific self-concept areas or it might be less reliable and valid for one of the grades. On the other hand, a separate test for each grade would not measure between-grade changes without elaborate equating procedures. Balancing time and costs against benefits, it was decided to develop the scale according to specifications and to study the results.

\section{Methodology of Scale Construction}

Items for this scale were constructed using homogeneous methods of scale construction. As a first step toward the construction of this scale, approximately 200 pieces of research were reviewed. Test items were constructed to reflect the results of those studies whose findings differentiated between persons with low and high self-concept. For example, a negative correlation between self-concept and anxiety has been found (Thompson, 1972). Accordingly, some test items measuring anxiety were constructed, such as the following: "Me preocupo mucho por los problemas que puedan surgir" (I worry a lot about problems that may come up). In addition, approximately 30 available self-concept instruments were reviewed. Their methods of approach to the problem and their item analysis results were studied. Items with high indices of discrimination or items that loaded highly on one of the self-concept related factors were considered for adoption. As a result, 290 test items were constructed in a draft form in Spanish. A dichotomous response format was used, with students indicating whether the item was or was not true most of the time. The Likert-type scale was not used because it had been previously employed in a fourth-grade scale with little success (Whitmore, 1975). Instead, it was decided to use dichotomous items and to include in the final scale a larger number of items than would have otherwise been employed.
A problem of major importance in the construction of this or any other scale in Puerto Rico is the attention that must be paid to the local culture and language. Self-concept, and individual's self-evaluation, has been defined in research according to Anglo standards of achievement and has been used with little change in instrument construction for Chicano children (Muller \& Leonetti, 1972). On the other hand, there are no research findings to support the view that it may be defined differently in Puerto Rico, an island that has been under United States control for the past 80 years. A study by Hernandez (1964) lists Puerto Rican adolescent problems and needs very similar to those in the mainland United States. It was therefore hypothesized that self-concept on this island could basically be measured in the same way as on the mainland. Evidence to support this hypothesis was offered in that many items developed on the basis of mainland United States correlates of self-concept had considerable discriminating power (see Table 3). The authors, however, recommend tentative use and careful investigation of items whose content has been validated in a culture other than that of intended use.

It was considered important to construct a scale whose language reflected the Spanish spoken by Puerto Rican children. Colloquial Spanish varies from country to country. The authors found a few scales in Spanish, mostly constructed for Mexican American (Chicano) children, but the language in itself was not always usable because constructions frequent among Chicanos are not used by Puerto Ricans. Also, test items could not be directly translated from English because of word frequency problems; the style of many items in scales that were directly translated was disappointing. The language problem was accompanied by the fact that neither author is Puerto Rican: One is a Peruvian who has lived in Puerto Rico for 10 years, and the other is a Greek, very fluent in Spanish, who lived on the island for 6 months. It was decided to enlist the aid of the school districts. Six school personnel members formed a 
committee that met with the authors several times. The committee reviewed all the items that had been developed and rephrased them, using the expressions Puerto Rican children use. Care was taken not to alter the meaning. With the committee's valuable help, 264 items were developed. The vocabulary used was such that fourth grade students could understand it. Though local expressions were used, no common grammatical errors were included. No item was longer than one and a half lines. Half of the items had negative syntactical constructions.

The 264 items were randomly separated into three forms of 88 in each. Then, the committee members took copies and administered them to small groups of students in their districts noting the time it took fast and slow readers of various grades to complete the forms, the words students did not know, expressions that were not clear, and reactions to the scale. As a result of the small group administration, several changes were made. It was found that younger students did not respond correctly to the items that contained negative constructions. Therefore, all negative constructions were changed into positive while the negative meaning was kept. The scoring key for the items was prepared according to the findings of the previously conducted literature search. Each item was to be given a score of " 1 " if answered in the direction that indicated high self-concept. The scale score was to be an unweighted total of items answered in the desirable direction.

\section{Method of Data Collection}

Classes containing a total of 3,134 4th, 7th, and 10th graders in equal numbers were selected at random following a sampling procedure routinely used by the Department of Education, whose main purpose is to include a proportionate number of rural and city students. Only public schools were sampled. The 264 items separated in three forms were administered to the students, who marked their answers on computer-scored sheets. Precise test instructions were prepared and sent to the teachers, who administered the forms to their classes.

The three forms were administered to the students, one each day during 3 consecutive days. This way each student took all three subsets of the item bank. Answer sheets were collected and data were analyzed by the Department of Education computer center. When data were processed, 690 answer sheets had to be eliminated as a result of incorrect or missing student numbers. Therefore, a total of 2,445 returns were used for data analysis.

\section{Item Analysis Results}

The main purpose of item analysis was to identify items that discriminated between students who scored high and low on the self-concept scale. The analysis was performed on the 264 items and gave difficulty and discrimination indices. The latter were phi coefficients computed for each item between numbers of "right" and "wrong" responses according to the scoring key and number of students whose total score was in the upper and lower $27 \%$. The distribution that resulted was negatively skewed and very leptokurtic. Split-half and Kuder-Richardson reliability coefficients computed for each scale ranged from .83 to .89 . The items that had phi coefficients of .4 or higher were selected for each grade separately, and selections for the three grades were compared.

Generally, there was agreement across grades. Thirty-four items had phi coefficients of .4 and above in all three grade levels. Fifty others showed phi coefficients of .4 to .6 for two grades, while in the third, coefficients ranged from .3 to .39. These 84 items were selected for a second analysis. Since the 10th grade was found to share slightly fewer items with phi coefficients of .4 with the other grades, nine more items were added that had coefficients of .3 to .39 at the other levels.

In the second analysis, which included 93 items, the score distribution approached normality much more, and the reliability coeffi- 
Table 1

Reliability Coefficients for the Self-Concept Scale

\begin{tabular}{|c|c|c|c|c|}
\hline \multirow{2}{*}{$\begin{array}{l}\text { Form and } \\
\text { Coefficient }\end{array}$} & \multicolumn{3}{|c|}{ Grade } & \multirow[b]{2}{*}{ Overall } \\
\hline & $\overline{4 t h}$ & $7 \mathrm{th}$ & 10 th & \\
\hline \multicolumn{5}{|l|}{ Long form (88 items) } \\
\hline $\mathrm{K}-\mathrm{R} 20$ & .92 & .94 & .94 & .93 \\
\hline Split-half & .92 & .93 & .93 & .93 \\
\hline \multicolumn{5}{|l|}{ Short form (34 items) } \\
\hline $\mathrm{K}-\mathrm{R} 20$ & .85 & .86 & .86 & .86 \\
\hline Split-half & .83 & .87 & .85 & .85 \\
\hline
\end{tabular}

cients rose. They ranged from .89 to .94 (see Table 1). Phi coefficients also increased; most items showed phi's of .4 and above in all three grades. The five least discriminating items were eliminated, leaving a scale with a total of 88 items. The 34 best discriminating items in all grade levels were analyzed separately, and it was found that they could provide a short form of the scale (see Table 3). Kuder-Richardson and splithalf reliability coefficients for the short form ranged from .83 and .87 (see Table 1).

The 88 selected items were classified on the basis of their content in four categories: (1) school and work (27 items); (2) peer relation- ships (23 items); (3) self-description (29 items); and (4) parent-student relationships (8 items). Preliminary norms in percentile form were developed for each grade level from existing data.

The scores obtained on the 88 selected items by the 2,445 students were correlated with the students' grade-point average (GPA) of the previous year. A Pearson correlation of .28 was obtained, which is significant at the .0001 level for this sample size. This is lower than the average of .5 reported by Bloom (1976), possibly because the GPA did not reflect current performance and possibly because GPA in Puerto Rico public schools reflects only Spanish, English, and math

Table 2

Scale Statistics

\begin{tabular}{lrrrr}
\hline Central Tendency and & \multicolumn{3}{c}{ Grade } & Overal1 \\
\cline { 3 - 4 } Dispersion Measures & 4th & 7th & 10th & \\
\hline Long form (88 items) & & & & \\
Mean & 67.90 & 69.83 & 72.44 & 67.66 \\
Standard Deviation & 13.15 & 14.15 & 13.45 & 10.01 \\
Skewness & -0.45 & -0.71 & -1.07 & -0.75 \\
Kurtosis & 2.41 & 3.00 & 4.29 & 3.71 \\
Short form (34 items) & & & & \\
Mean & 24.39 & 25.02 & 26.04 & 25.08 \\
Standard Deviation & 6.19 & 6.36 & 5.85 & 6.17 \\
Skewness & -0.47 & -0.70 & -1.04 & -0.75 \\
Kurtosis & 2.31 & 2.84 & 3.78 & 3.14 \\
\hline
\end{tabular}


ing updated and more comprehensive indicators of academic achievement should clarify this point.

\section{Discussion}

The scale that was developed seems to have high internal consistency reliability in all three grade levels. Its reliability was highest at the 7 th grade level because this grade shared many highly discriminating items with the other two (see Table 1).

The method of homogeneous scale construction used for item construction provides a basis for the construct validity of the scale. The content of the items is in many respects similar to that of other school age self-concept scales. The correlation with previous year's grade point average served as an indicator of criterion-related validity.

Mean self-concept scores increased from one grade to the next (see Table 2). This is consistent with previous findings (Thompson, 1972). At each grade level the score distribution also became more negatively skewed $(-.45,-.71$, and -1.07 , respectively). Small percentages of students received nearly "perfect" scores $(1 \%, 4 \%$, and $4 \%$ in each grade level), but there were no

Table 3

The Ten Nost Discriminating Items and Overall Phi Coefficients

Item

Phi

7. Generalmente estoy atrasado (a) en mi trabajo. (I am generally behind with my work.)

16. Soy más lento (a) que mis compañeros para hacer los trabajos de la clase.

(I am slower than my classmates in doing homework.)

24. Muchas veces me siento completamente inútil. (Many times I feel completely useless.)

26. Muchas veces dejo las cosas sin terminar. (Many times I leave things unfinished.)

33. Generalmente, los maestros me hacen preguntas difíciles de contestar. (Teachers generally ask me difficult questions.)

44. Se me olvida fácilmente 10 que aprendo.

( $I$ easily forget what I learn.)

53. A menudo me da coraje.

(I often get angry.)

55. Si la maestra hace una pregunta tengo miedo

de contestar.

( $I$ am afraid to answer if a teacher asks a question.)

60. Mis maestros me ponen a hacer cosas tan difíciles, que no puedo hacerlas.

(Teachers make me do things that are too difficult for me.)

62. Quisiera ser otra persona.

(I would like to be someone else.)

Escala de Autoconcepto, 1980 
scores approaching zero. This indicates that the scale can successfully be used for the identification of students in all three grade levels who have a low self-concept.

A strong effort was made to balance the numbers of positive and negative items. The most discriminating items, however, tended to be negative. As a result, the 88 -item scale contains only $33 \%$ positive items. It seems that it is the lack of a negative quality rather than the existence of a positive quality that characterizes students with high self-concepts in the public schools of Puerto Rico.

The short form of the scale could be used for data collection from groups, particularly if time is very limited, since only a few minutes are necessary for its administration. The 88-item scale can be administered within a 50-minute class period to 4 th graders and in much less time (20 to 30 minutes) to upper grades. It is reliable and broad enough in content to permit self-concept assessment of individual students in the Puerto Rico public schools who have third grade reading skills (see a sample of items in Table 3 ). More statistical work on the scale can produce a set of subscores that will focus on relations with school, peers, and descriptions of self.

Further research is necessary. The divergent validity of the scale regarding reading skills and comprehension must be measured. Test-retest reliability should be established, as well as a correlation with an external criterion of self-concept. If administratively possible, the scores should be correlated with current grade point averages that include all subjects taken. Norms based on the final format of the scale should be established and supplemented with private school data if private schools in Puerto Rico are to use this instrument. It might also be possible to use this scale to assess the self-concept of Puerto Rican children in the continental United States if it is established that they have adequate reading and language skills in Spanish to respond to it.

\section{References}

Bloom, B. Human characteristics and school learning. New York: McGraw-Hill, 1976.

Brookover, W. B., Patterson, A., \& Thomas, S. Selfconcept of ability and school achievement. East Lansing, MI: U.S. Office of Education, Cooperative Research Project No. 845, East Lansing Office of Research \& Publications, Michigan State University, 1962.

Campbell, P. B. School and self-concept. Educational Leadership. 1967, 24, 510-515.

Coppersmith, S. The antecedents of self-esteem. San Francisco: W. H. Freeman \& Company, 1967.

Cronbach, L. Essentials of psychological testing (3rd ed.) New York: Harper \& Row, 1970.

Fink, M. B. Self-concept as it relates to academic achievement. California Journal of Education Research, 1962, 13, 57-62.

Fitts, W. H. The self-concept and human behavior. Mental Health Center Research Bulletin, 1965, 1, 1-78. (Monograph)

Gill, M. P. Patterns of achievement as related to the perceived self. Paper presented at the annual meeting of the American Educational Research Association, Los Angeles, CA, April 1969.

Gordon, I. J. Studying the child in the school. New York: John Wiley \& Sons, 1966.

Hernández, M. Necesidades y problemas de los estudiantes adolescentes de escuela superior en Puerto Rico. Hato Rey, Puerto Rico: Departamento de Instrucción Pública, Oficina de Evaluación, 1964.

Muller, D. G., \& Leonetti, R. Primary Self-Concept Scale: Test Manual. Ft. Worth, TX: National Council for Bilingual Education, 1972 (ERIC Document Reproduction Service, No. ED 062847).

Puerto Rico Departamento de Instrucción Pública, Centro de Evaluación. Escala de autoconcepto. Hato Rey, Puerto Rico: Author, 1980.

Purkey, W. W. Self-concept and school achievement. Englewood Cliffs, NJ: Prentice-Hall, 1970.

Richmond, B. O., \& White, D. F. Sociometric predictors of the self-concept among fifth- and sixthgrade children. Journal of Educational Research. 1971, 64, 425-429.

Stanwyck, D. J., \& Felker, D. W. Measuring the selfconcept: a factor analytic study. Paper presented at the annual meeting of the National Council of Measurement in Education, New York, April 1971. (ERIC Document Reproduction Service No. ED 053161) 
Thompson, W. Correlates of the self concept (Monograph No. 6). Nashville, TN: Dede Wallace Center, 1972.

Whitmore, J. R. Thinking about my school, TAMS: The development of an inventory to measure pupil perception of the elementary school environment (R \& D Memorandum No. 125). Palo Alto, CA: Stanford University, Stanford Center for Research and Development in Testing, 1975. (ERIC Document Reproduction Service, No. ED 100998)

\section{Acknowledgment}

The authors thank the Evaluation Office of the Departamento de Instrucción Pública and staff for their support. Data on which this paper is based may be obtained directly from the Evaluation Office, Departamento de Instrucción Pública, Hato Rey, Puerto Rico 00919.

\section{Author's Address}

Send requests for reprints or further information to Helen Abadzi, Psychology Department, University of Texas at Arlington, Arlington, TX 76019. 